\title{
Hong Kong's Currency and Monetary Policy
}

\author{
http://doi.org/10.21272/fmir.5(3).33-38.2021
}

Richard Fast, ORCID: https://orcid.org/0000-0002-9779-1659

\author{
M.A., Economics, Troy University, USA
}

\begin{abstract}
This literature review is a synopsis of what has been written on the currency and monetary policy of Hong Kong since its relinquishment from Great Britain in 1999. In particular, this paper examines the role and policies of the Hong Kong Monetary Authority, the island province's equivalent to a central bank. Since Hong Kong does not have a central bank per se, it is interesting to note how the money supply is created and maintained, and what its relationship is to mainland China. This institution makes Hong Kong unique among developed economies, which typically have a central bank that oversees monetary creation and policy. The Literature Review is composed of two parts: Part One will cover the revaluation of the Hong Kong Dollar with regard to its value relative to the currencies of China, Japan, Europe, and the United States, particularly during financial crises. This part of the literature review will cover the work of Chan (2002), Schenk (2004), Shah (1996), Cook and Yetman (2004), and Ma and Cheng (2014) as they use different measurement methods to monitor the change in the Hong Kong Dollar's value over time, especially compared to the period before the creation of the Hong Kong Dollar. Part Two will cover the monetary and macro-economic policies and currency board effectiveness of the Hong Kong Monetary Authority in sustaining the value of the Hong Kong Dollar. This part of the literature review will cover the work of Chen (2001), Siregar and Walker (2000), Chen and Tsang (2020), Funke and Paetz (2000), and Huang and Shen (2017). This paper also includes a section on suggestions for future research, including what effect the shift of pegging the Hong Kong Dollar (HKD) to other currencies, such as the Euro or the Japanese Yen, or when interest rates in other countries are set at zero. The paper wraps up with an overview of the literature discussed and possible paths going forward, including recreating the studies over time to see how effective such a maneuver has been in practice when compared to competing currencies. Followers of the Hong Kong Dollar will especially find these results useful as they seek to exchange currencies for the highest value.
\end{abstract}

JEL Classification: E0, E5, E6, P1.

Keywords: Hong Kong, monetary policy, Hong Kong Dollar, Hong Kong Monetary Authority, currency, currency boards.

Cite as: Fast, R. (2021). Hong Kong's Currency and Monetary Policy. Financial Markets, Institutions and Risks, 5(3), 33-38. http://doi.org/10.21272/fmir.5(3).33-38.2021

Received: 28, July, $2021 \quad$ Accepted: 17, August, $2021 \quad$ Published: 13, September, 2021

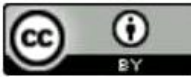

Copyright: (C) 2021 by the author. Licensee Sumy State University, Ukraine. This article is an open access article distributed under the terms and conditions of the Creative Commons Attribution (CC BY) license (https://creativecommons.org/licenses/by/4.0/)

\section{Introduction}

Hong Kong has in the past few decades earned a reputation for being a shining example of laissez-faire capitalism. Despite its small size and becoming a part of China in 1999 under the guise of "one country, two systems", the island province has proved to be one of the wealthiest parts of the world. Even today, the island maintains a standard of living higher than most of the rest of Asia and indeed, the world. However, that also comes with huge inequality in income.

This literature review will cover Hong Kong's currency and how its currency board operates its monetary policy. Central banks exist to inact monetary and macroeconomic policy. Hong Kong does not have a central bank- instead, it has a currency board, the Hong Kong Monetary Authority. The territory's currency, the Hong Kong dollar (HKD), is different than the Chinese yuan in several respects. The HKD is pegged to the U.S. dollar at a ratio of HKD $\$ 7.80=$ USD $\$ 1$, which makes it more stable than the Chinese yuan or renimbi. Additionally, most businesses in Hong Kong will only accept HKDs, not Chinese yuan. The papers discussed below can be separated into two broad categories: the revaluation of the HKD, particularly during financial crises, (Chan 2002, Schenk 2004, Shah 1996, Cook and Yetman 2004, Ma and Cheng 2014) and the 
monetary/macroeconomic policies and effectiveness of the currency board (Chen 2001, Siregar and Walker 2000, Chen and Tsang 2020, Funke and Paetz 2000, Huang and Shen 2017). As we will see, the HKD appreciates in value when the HKMA takes a more hands off approach. This is beneficial to the people of Hong Kong, obviously, but also to investors and the global monetary community.

The remainder of the paper is outlined as follows: Section 1 is the literature review, Section 2 is a source of ideas for future research, and Section 3 is the conclusion. Finally, attached is a list of works cited.

\section{Literature Review}

This section will be divided into two parts. The first part will be regarding the revaluation of the Hong Kong Dollar (HKD), particularly during financial crises (Chan 2002, Schenk 2004, Shah 1996, Cook and Yetman 2004, and Ma and Cheng 2014). The second part will be regarding the monetary and macroeconomic policies as well as effectiveness of the currency board (Chen 2001, Siregar and Walker 2000, Chen and Tsang 2020, Funke and Paetz 2000, and Huang and Shen 2017). The purpose for this division is to more accurately examine the different aspects of Hong Kong's monetary policies.

\section{Part I: Revaluation of the HKD}

This first part will cover the revaluation of the Hong Kong Dollar (HKD), particularly during crises. In this part we will cover Chan (2002), Schenk (2004), Shah (1996), Cook and Yetman (2004), and Ma and Cheng (2014). We will analyze some of the similarities and differences that these authors use in modeling the currency's change in value. The first work we will consider is "Currency Substitution, Between the Hong Kong Dollar and the Renminbi in South China" by Kenneth S. Chan (2002). In this paper, Chan explores the fluctuating exchange rate between the island province's currency to that of two Sourthern Chinese provinces, Macau and Guangdong. The context of this paper is the currency crisis that occurred in Asia in the late 1980s and early 1990s. Chan explains that during this time of crisis that the use of the Hong Kong dollar (HKD) is considered a "safe" haven currency to store value and the fluctuating exchange rate should not cause too much imbalance when mainland Chinese convert their renminbi into HKD. The goal of this paper is to build upon the existing literature by showing the demand of HKD by foreigners during the currency crisis. Guangdong is one of the fastest growing provinces in mainland China and so many residents quickly traded their renminbi into HKD to preserve the value of their wealth, great or small. Chan uses the common metrics of tracking U.S. dollars (USD) overseas as the method of tracking HKD trading by those outside of the island province. Through the use of estimated mathematical models, Chan finds that 7.4 percent of the currency issued in Hong Kong is used for transactions in Guangdong, and 3.2 percent of HKD is used for transactions in Macau. Through the use of regressions, Chan shows the demand trends for HKD in these two mainland provinces and concludes that the foreign demand for HKD in this turbulent period should not be a problem for Hong Kong, at least in the short run, because the HKD used in Guangdong and Macau are only used for transactions. Finally, Chan acknowledges that his paper does not take into account black market exchange rates and the effect that has on demand for the currency, future research could look into that.

The next paper that we will examine is "The Empire Strikes Back: Hong Kong and the Decline of Sterling in the 1960s" by Catherine R. Schenk (2004). In this paper, Schenk explores the effect that Hong Kong protests in favor of re-claiming its sovereignty in the 1960s had on the devaluation of the currency as still a colony of Great Britain. In its global empire, the British had set up bank branches around the world that remained under the constitutional power of the crown. Britain wanted Hong Kong to hold reserves preferably in sterling or also gold, but Hong Kong wanted to hold reserves in its own currency, the HKD. Hong Kong saw this as a means of asserting its sovereignty. Schenk explains that this currency conflict resulted in Britain ultimately giving in to Hong Kong and letting them have their own currency because Britain's economy was in shambles and could not afford to maintain its global empire. Thus, Hong Kong, while still under the protectorate of Britain, monetarily established self-rule. This paper gives some context to three upcoming papers we will examine: Chan (2002), Chen (2001), and Siregar et al (2000).

The next paper that we will examine is "Hong Kong's Indeterminacy Puzzle: Institutionalist and Econometric Approaches" by Parth J. Shah (1996). In this paper, Shah explains that between 1974-83, Hong Kong had free flowing exchange rates, money supply, and price level in what is called the indeterminate period. This paper takes two approaches, one institutionalist and the other econometric, to analyzing fluctuations in the price level in the indeterminate period in the context of a fiat currency with no central bank. Granger and Granger-Akaike 
Financial Markets, Institutions and Risks, Volume 5, Issue 3, 2021 ISSN (online) - 2521-1242 ISSN (print) - 2521-1250

tests are utilized to monitor the exchange rate and price level fluctuations. Shah states that " $\mathrm{t}] \mathrm{he}$ Granger test shows 'independence' among money supply, prices, and exchange rate in Hong Kong. The Granger-Akaike test indicates that a unidirecitonal relationship from exchange rate to prices to money supply, implying that Hong Kong's money supply and prices were not indeterminate during 1974-1983." The results are inconclusive (no cross-verfication). Thus, Shah ends by saying that both approaches should be used to give a better picture of the situation. This paper is significant because it shines light on the nature of supply of and demand for freefloating currencies, in this case the HKD, in the timeframe that the U.S. and other countries were experiencing stagflation.

The next paper that we will examine is "Currency Boards When Interest Rates Are Zero" by David Cook and James Yetman (2014). In this paper, the authors explore the question of how countries with a currency board, not a central bank, handle the revaluations of their currency when interest rates are zero and the possibility of the fixed exchange rate being abandoned. In this case, the exchange rate is between the HKD and the USD, which has been the case since October 1983. It is within this context that Hong Kong's currency board has increased its foreign exchange reserves since 2008. When interest rates are zero, the HKD appreciates. Conversely, when interest rates fluctuate, the HKD depreciates. Cook et al (2014) seek to use "a new machinism, based on central bank balance sheets, to establish equilibrium in currency markets when interest rates are zero." This "new mechanism" is a model to show that the above is true, given that currency boards, Hong Kong's in particular, have very limited discretion. This paper is significant because it demonstrates the resiliency of the HKD as compared to other currencies.

The next paper that we will examine is "An Optimal Currency Basket to Minimize Output and Inflation Volatility: Theory and an Application to Hong Kong" by Zihui Ma and Leonard K. Cheng (2014). In this paper, the authors explore the idea of an optimal currency basket for a small country and apply it to the Chinese island province. Ma and Cheng (2014) take an optimal currency basket and compare it to the Hong Kong currency board's operations. This currency basket is chosen with the assumption that it will "minimize the average of its expected output volatility and expected inflation volatility." What they found was that the optimal currency basket depends on Hong Kong's heaviest trading partners, which includes Mainland China and their currency, the renminbi, as well as the U.S., Japan, and the Eurozone.

This concludes the first part of the literature review. So far we have examined how the Hong Kong Dollar has been revaluated in the past, particularly during financial crises. This analysis gives us some context to how the currency is managed as we move on to the second part of the literature review. From here, we will observe Hong Kong's monetary and macroeconomic policies from a broader perspective to see how effective the currency board is, relative to other developed nations.

\section{Part II: Monetary/Macroeconomic Policies and Currency Board Effectiveness}

This second part will cover the monetary and macroeconomic policies adopted by the Hong Kong Monetary Authority (HKMA), either on its own or as a reaction to the policies of the central banks of other countries. In this part we will cover Chen (2001), Siregar and Walker (2000), Chen and Tsang (2020), Funke and Paetz (2000), and Huang and Shen (2017). We will analyze some of the similarities and differences in technique that these authors use to track the effects of the HKMA's monetary policy.

The first paper we will consider is "The Hong Kong Currency Board During the 1997-8 Crisis: Problems and Solutions" by Nai-fu Chen (2001). In this paper, Chen explores the Asian financial crisis of 1997 and how the Hong Kong Monetary Authority could not handle the speculations of the currency with high volatility of interest rates. The paper explores some solutions to the crisis, including preventing against devaluation of the HKD. The paper introduces the concept of a currency board which is intended to oversee the currency, first imposed during colonial times by the British. Chen explains that a currency board is different from a central bank in that it has no monetary policy. Instead, the currency board is supposed to exchange the HKD to the linked foreign currency when requested. Because it has very limited discretionary power, the currency board has more credibility than a central bank might. Chen concludes by proposing that the currency board keep $100 \%$ reserves in the linked foreign currency (USD) to insure the stability of the monetary system, instead of the current system that operates under a fractional reserve banking system. This paper differs from Chan (2002) in that it focuses on the internal management of the $\mathrm{HKD}$, as opposed to outside trading and transactions.

However, both papers use mathematical models to show that demand for the HKD is strong both internally and externally in times of crisis. 
The next paper we will examine is "Monetary Shocks and the Fundamental Determinants of the Real Exchange Rate under the Hong Kong Currency Board" by Reza Yamora Siregar and W. Christopher Walker (2000). In this paper, the authors examine monetary shocks on the part of the Hong Kong Monetary Authority (HKMA) which suggest that money is not neutral. The authors note that even during the crisis and despite overvaluations and undervaluations, the HKD has remained more stable than most other Asian currencies. This paper has more in common with the previous paper, Chen (2001) than Chan (2002), as it deals with the effects of the HKMA with regard to the value of the HKD.

The next paper that we will examine is "Impact of US Monetary Policy Rate Shock and Other External Shocks on the Hong Kong Economy: A Factor-Augmented Vector Autoregression Approach" by Hongyi Chen and Andrew Tsang (2020). In this paper, the authors draw on the work of former Federal Reserve chairman Ban Bernanke to show that Hong Kong is resilient against external shocks to its economy, in particular banks' liquidity. This is important because what other central banks, such as the Federal Reserve (Fed), the European Central Bank (ECB), and the Bank of Japan (BoJ), do has an effect on Hong Kong and its monetary policy. Suppose that the Fed injects a bunch of stimulus into the U.S. economy, how does that effect Hong Kong? Not much, this paper shows, because Hong Kong has sound macroeconomic policies, unlike other countries. Since the HKD is linked to the USD, what the Fed does in the U.S. has a similar effect in Hong Kong. This paper is more recent than the others and is most relevant to the current situation.

The next paper that we will examine is "Dynamic Stochastic General Equilibrium - Based Assessment of Nonlinear Macroprudential Policies: Evidence from Hong Kong" by Michael Funke and Michael Paetz (2018). In this paper, the authors show that central banks the world over were ill-equiped to handle the 2007-8 financial crisis and that what actions they did take were the wrong actions. They then focus on Hong Kong as an example of an economy that already had an unstable housing market, given the island province's limited geographic area, and the macroeconomic business cycle. While many countries tried to reform their monetary and macroeconomic policies to prevent, or at least mitigate, the effect of such financial crises from happening again, Hong Kong reformed its tax-based policies. This paper shows that those reforms did not negatively impact the housing market cycle. This approach differs from the other papers we have reviewed in that, first, it is more recent, and second, that it explores different options rather than what had already happened.

The next paper that we will examine is "Residential Housing Bubbles in Hong Kong: Identification and Explanation Based on GSADF Test and Dynamic Probit Model" by Juan Huang and Geoffrey Qiping Shen (2017). In this paper, the authors explore whether Hong Kong's high housing price is a bubble and whether the speculative demand of investors and an increase in the money supply is driving up housing costs. Investors, they assert, would prefer mass housing more than luxury housing since mass housing has proven to be more lucrative. However, mass housing is prone to more bubbles than luxury housing. In this case, both are the subject of a major housing bubble. In addition, the authors also speculate that U.S. monetary policy, specifically increasing the money suppy, is also contributing to driving up housing costs in Hong Kong. Huang and Shen (2017) use a Dickey-Fuller test and dynamic probit models to answer this question. What they found was that " $[\mathrm{u}]$ nder the linked exchange rate system, the increase of money supply of Hong Kong Government, caused by the US loose monetary policies, serves as a positive shock and contributes to the initial increase of housing price." The Hong Kong government responded to this problem by attempting to increase the supply of land and restrict new applications for immigration. However, this creates the additional problems of the cost of creating new space and curbing the free flow of goods and people; in other words, government is making the housing problem worse. This paper is significant because it shows how an increase in the money supply affects the Hong Kong housing market. None of the other papers we've looked at so far show this real-world effect to everyday Hong Kongers.

This concludes the second part of the literature review. So far we have analyzed what monetary and macroeconomic policies the HKMA has taken to strengthen the position of the HKD, relative to other developed nations. We have seen that Hong Kong is for the most part resilient to the monetary policies enacted by other countries' central banks. However, there is still a role for discretionary action on the part of the HKMA to prevent unhealthy volatility in the currency. From here we will move on to what future research can do help deepen our understanding of the HKMA's effectiveness and what the currency board can or should do moving forward. 


\section{Future Research}

This section will cover areas of the preceding research that could be expanded upon or updated with newer data. Emphasis is placed on the revaluation of the HKD and the role of the HKMA. Future research in these areas will facilitate the understanding of how a currency board should operate with best practices, a historical record to see what errors to avoid going forward, and what monetary policies have proven to be successful for a strong HKD.

With Ma and Cheng (2014), the authors state that the study should be redone in a few years once new data become available. The same currency basket used in 2024, for example, could be significantly less optimal than it was in 2014. It will be interesting to see what effect the Coronavirus has had on these countries' economies and how that has impacted the value of their currencies in relation to the Hong Kong dollar. With Chan (2002), future research could focus on the black market exchange rates and the effect that has on demand for the currency. With Funke and Paetz (2018), the same study could be repeated in 2028 to see if anything had changed. This would tell us the effect that monetary policy has on the Hong Kong housing market; for example, to see whether the supply of new housing increases or decreases as the value of the HKD increases or decreases. With Shah (1996), the author admits that the results are inconclusive, so future research could could focus on cross-verification between the institutionalist and econometric approaches of Granger and Granger-Akaike tests of a currency without a central bank against an optimal basket of other currencies. With Huang and Shen (2017), further research could be done on what effect U.S. monetary and macroeconomic policy has on the HKD and the standard of living of everyday Hong Kongers. With Siregar and Walker (2000), future research could be done on what additional monetary shocks have been implemented by the HKMA since 2000 and what effects those have had on the purchasing power of the HKD. With Schenk (2004), future research could be done on what other countries under the British banking crown did to establish their own monetary independence. With Cook and Yetman (2014), future research could be done on how the HKMA compares to other countries that also have currency boards and not central banks, both in the present and over time. With Chen (2001), future research could focus on what would happen if the HKMA changed the linked foreign currency from the USD to another currency, such as the Euro or Japanese Yen, to see what effect that would have on the stability and value of the HKD over time. Finally, with Chen and Tsang (2020), future research could be done on what other external shocks by the Fed, ECB, and BoJ since 2020 have occurred and what effect, if any, they have had on the HKD.

Much of the above suggested future research advises re-doing the studies after some time has passed in order to gage the long term real effects of such external monetary shocks and macroeconomic policies. This would be useful because it will help us understand what are the proper conditions in order to achieve stability and maintain, if not increase, the value of the HKD. Countries with a central bank could learn how to improve the status of their currency by converting to the functions of a currency board instead, with limited discretion but a more powerful hard currency.

\section{Conclusion}

This literature review has surveyed ten academic papers on Hong Kong's currency, the Hong Kong dollar, and Hong Kong's currency board, the Hong Kong Monetary Authority. What we found is that Hong Kong is exceptional in the sense that it has a currency board but no central bank, which is very limited in its discretionary powers. This allows Hong Kong to have more free market monetary policies than most other countries. The Hong Kong dollar is tied to the U.S. dollar, which gives it stability relative to other Asian currencies, however that also means that Hong Kong is subject to the adverse effects of loose U.S. monetary policy.

This literature review has uncovered a number of issues relating to the HKD and the HKMA. We have examined how an optimal currency basket might compare to the traditional currency pegged model (Ma and Cheng 2014) as well as how an increase in the money supply affects Hong Kong housing costs (Huang and Shen 2017). Also covered were how interest rates of zero affect the revaluation of the HKD (Cook and Yetman 2014) and how the free-flowing exchange rates, money supply, and prices during the 1974-1983 period interact with each other (Shah 1996). We have also seen that the HKMA reformed its tax-based policies to help deal with its housing crisis (Funke and Paetz 2018) and that Hong Kong is resilient against external shocks to its economy by foreign central banks, particularly by the Federal Reserve, Bank of Japan, and the European Central Bank (Chen and Tsang 2020). We have also seen that colonial Hong Kong in the 1960s was willing to devalue its currency by rejecting Britain's insistence on sterling and gold in favor of the HKD as a means of 
establishing their sovereignty (Schenk 2004). In addition, we have seen that despite the HKMA fiddling with the money supply, the HKD is still more resilient than other Asian currencies (Siregar and Walker 2000) and that the financial crisis of 1997 should have caused the HKMA to keep 100\% reserves in foreign currencies (Chen 2001), but it did not. Finally, we have seen how the HKD exchange rate has fared in two South China provinces, Guangdong and Macau (Chan 2002). Hopefully, the HKMA will heed these analyses going forward and maintain a more sound monetary policy.

\section{References}

1. Chan, K. S. (2002). Currency Substitution, between the Hong Kong Dollar and the Renminbi in South China. Pacific Economic Review, 7(1), 37-50. [Google Scholar]

2. Chen, N. (2001). The Hong Kong Currency Board During the 1997-8 Crisis: Problems and Solutions. International Review of Finance, 2(1/2), 99. [CrossRef]

3. Siregar, R. Y. \& W. Christopher Walker. Monetary Shocks and the Fundamental Determinants of the Real Exchange Rate under the Hong Kong Currency Board. Asian Economic Journal, 14(1), 1. [Google Scholarl

4. Schenk, C. R. (2004). The Empire Strikes Back: Hong Kong and the Decline of Sterling in the 1960s. Economic History Review, 57(3), 551-580. [Link]

5. Chen, H. \& Tsang, A. (2020). Impact of US Monetary Policy Rate Shock and Other External Shocks on the Hong Kong Economy: A Factor-Augmented Vector Autoregression Approach. Pacific Economic Review, 25(1), 3-20. [Google Scholar]

6. Funke, M. \& Paetz, M. (2018). Dynamic Stochastic General Equilibrium - Based Assessment of Nonlinear Macroprudential Policies: Evidence from Hong Kong. Pacific Economic Review, 23(4), 632-657. [Google Scholar]

7. Shah, P. J. (1996). Hong Kong's Indeterminacy Puzzle: Institutionalist and Econometric Approaches.” Australian Economic Papers, 35, 348. [Google Scholar]

8. Cook, D. \& Yetman, J. (2014). Currency Boards When Interest Rates Are Zero. Pacific Economic Review, 19(1), 135-151. [Google Scholar]

9. Huang, J. \& Qiping, G. S. (2017). Residential Housing Bubbles in Hong Kong: Identification and Explanation Based on GSADF Test and Dynamic Probit Model. Journal of Property Research, 34(2), 108-128. [Google Scholar]

10. Ma, Zihui, and Cheng, L.K. (2014). An Optimal Currency Basket to Minimize Output and Inflation Volatility: Theory and an Application to Hong Kong. Pacific Economic Review, 19(1), 90-111. [Google Scholar] 